\title{
Actor- network theory (ANT): uma tradução para compreender 0 relacional e o estrutural nas redes interorganizacionais?
}

\author{
Jackeline Amantino- de-Andrade*
}

\section{Resumo}

Este ensaio propõe abordar a actor-network theory na análise relacional de redes interorganizacionais, considerando que outras abordagens apresentam limitações, por sustentarem uma divisão entre estrutura e agência. Para consubstanciar essa proposição, primeiramente, é apresentada uma revisão das abordagens de rede nas ciências sociais e, especificamente, nos estudos organizacionais, procurando demonstrar suas distinções, suas inter-relações e sua comum limitação ao se apoiar no estrutural em detrimento do relacional. Em seguida, é apresentada a actor-network theory, com destaque para sua capacidade de integrar o relacional e o estrutural na compreensão dos fenômenos de ordenação; procurando também se evidenciar as aplicações verificadas no campo dos estudos organizacionais. Finalmente, são consideradas as críticas a essa abordagem, ressaltando a diferença de pressupostos, bem como a sua capacidade de trazer contribuições para questões ainda não completamente respondidas, principalmente, quando considerados os fenômenos interorganizacionais.

Palavras-chave: redes; relações interorganizacionais ; teoria do ator-rede.

\begin{abstract}
This essay presents the actor-network theory (ANT) to analyze inter-organizational networks with intention to pass over the gap between agency and structure. Fist it is introduced a review of network theory in social sciences especially about organization studies to distinguish structural and relational approaches. After it is presented the ANT and some studies developed using this approach to understanding the ordering phenomena. To conclude it discusses the ANT's critics to compare its contributions to the comprehensiveness of inter-organizational relations.
\end{abstract}

Keywords: networks; interorganizational relations; actor-network theory.

\section{Introdução}

Nas últimas décadas, o conceito de rede tem sido utilizado como uma idéia norteadora para diversas disciplinas nas ciências sociais, não sendo diferente no campo dos estudos organizacionais. Neste, a abordagem do conceito de rede emergiu, principalmente, na tentativa de compreender os fenômenos interorganizacionais, de maneira que esse conceito surge como forma explicativa do relacionamento entre firmas, a partir de diferentes perspectivas. É o caso de perspectivas simétricas, focando relações horizontais de cooperação, como, por exemplo, as alianças estratégicas (GULATI, 1998). É igualmente o caso de outras perspectivas, que - também fazendo referência à cooperação e à confiança no relacionamento entre empresas - focam relações assimétricas e verticais nas denominadas cadeias produtivas (JONES, HESTERLY e BORGATTI, 1997).

No entanto, cabe salientar que a análise de redes interorganizacionais não está limitada ao contexto das firmas e de suas relações. Evidentemente, não se quer aqui fazer referência à banalização do conceito de rede depois da world web wild (LATOUR, 1999), mas destacar a amplitude dos relacionamentos interorganizacionais que têm sido analisados, a partir de uma abordagem de rede. Como exemplo, o caso da integração de ações e programas entre agências na prestação de serviços públicos (PROVAN e MILWARD, 1995).

É justamente essa diversidade de contextos e a própria complexidade das relações que se quer abordar com o conceito de rede que geraram uma vastidão fragmentada na literatura sobre relações interorganizacionais (OLIVER, 1990). Isso significa que a variedade de enfoques teóricos adotados não assegura uma clara 
acumulação do conhecimento ou mesmo uma consolidação conceitual, revelando uma segmentação na pesquisa sobre redes (OLIVER e EBERS, 1998).

Contudo, é importante observar que essa segmentação reflete o desafio de analisar as relações interorganizacionais a partir do imbricamento entre as dimensões econômica, social e política implícitas. Nesse sentido, Oliver e Ebers (1998) indicam um direcionamento para focos específicos como governança, estratégia e relações sociais, destacando-se uma escolha por teorias também específicas, como, por exemplo, a teoria da dependência de recursos, a teoria de custos de transação, a teoria das redes sociais etc.

Na realidade, esses enfoques procuram privilegiar a análise das redes interorganizacionais, a partir de uma perspectiva estrutural, na qual se quer determinar novas formas de governança e controle a partir de relações de cooperação e confiança. E à medida que essas análises focam estruturalmente as redes, muitos aspectos relacionais e processuais são deixados de lado, apesar de serem abordados marginalmente.

O objetivo deste ensaio é apresentar uma revisão teórica da abordagem de redes, tanto no contexto das ciências sociais quanto dos estudos organizacionais, estabelecendo distinções e limites da sua capacidade interpretativa dos fenômenos interorganizacionais, principalmente, no que concerne à dinâmica relacional. Este ensaio também pretende propor a abordagem trazida pela actor-network theory, que ao focar o processo de networking, contempla tanto os aspectos relacionais quanto os estruturais em contextos indistintamente imbricados.

\section{As redes nas ciências sociais}

Para Marques (2000, p.31) a abordagem de redes pode ter três usos no campo das ciências sociais. Em primeiro lugar, como metáfora, uso mais comum e disseminado, em que se quer expressar a noção de que entidades, indivíduos ou mesmo idéias estão de alguma forma conectados entre si. Em segundo lugar, as redes são concebidas normativamente, determinando certas configurações de um dado conjunto de entidades. Finalmente, é feita a abordagem das redes quanto à especificidade da análise de redes sociais, não considerando-a apenas como um aspecto estruturador, mas também, como método de descrição e análise das relações nelas presentes.

De acordo com Emirbayer e Goodwin (1994), a análise de redes surgiu como uma nova abordagem nas ciências sociais, ainda em meados de 1970, trazendo uma gama de metodologias diversas, cuidadosamente distinguidas a partir de três perspectivas principais: cultura, agência e estrutura e - em oposição aos pressupostos de integração normativa do estruturalismo-funcionalista - objetivando construir uma ponte para o gap micro-macro. Em outro artigo, Emirbayer (1997) define a abordagem de redes nas ciências sociais não como uma teoria ou um conjunto complicado de técnicas de pesquisa, mas como uma nova perspectiva analítica para o estudo sobre como recursos, bens e até mesmo posições fluem através de figurações particulares do social.

No entanto, é Mark Granovetter quem aproxima o campo dos estudos organizacionais da abordagem de redes sociais. Ainda em 1973, Granovetter apresenta o estudo de redes, numa perspectiva que pretensamente procura integrar o micro aos padrões do macro, transpondo uma fraqueza comum na teoria sociológica, que é a de compartimentar agência e estrutura em campos distintos de análise, a partir da idéia de laços fracos (weak ties) como elementos estruturadores.

Posteriormente, Granovetter (1985, p.481) apresenta sua sociologia econômica a partir do questionamento sobre "como comportamento e instituições são afetados pelas relações sociais?", desenvolvendo o conceito de imbricamento (embeddness), originário de Polanyi e amplamente adotado na análise organizacional (UZZI, 1996, 1997 e GULATI e GARGIULO, 2000). A questão é colocada quanto ao problema da ordem e da confiança na vida econômica, a partir da análise de padrões de relação que não se limitam a uma perspectiva subsocializada, típica do pensamento econômico da ação racional utilitária, nem tampouco a uma perspectiva sobre-socializada, que limita a ação às regras, normas e valores instituídos. Isso levou Granovetter (1985) a concluir que a ação está imbricada numa progressiva rede de relações. 
Granovetter propõe, então, compreender a construção social das instituições econômicas:

"As instituições econômicas não emergem automaticamente em resposta às necessidades econômicas. Mas, são construídas por indivíduos, aos quais as ações são facilitadas e restringidas por recursos e estruturas disponíveis nas redes sociais em que estão imbricados" (GRANOVETTER, 1992, p.7).

Segundo Callon (1999), Granovetter tateia de certa forma a actor-network theory, quando não considera a rede como um conjunto de entidades conectadas que já estão ali, mas como ontologias configuradas. Entretanto, observa que na sua oposição entre homo economicus e homo sociologicus - por meio da crítica à subsocialização e à sobre-socialização - Granovetter fica aprisionado no homo clausus, incapaz de lidar com situações de radical incerteza, na medida em que a agência depende de uma morfologia de relações na qual está envolvida. Callon parece indicar em Granovetter, um aprisionamento ainda estrutural, tendo em vista que a questão não é explicar o fato (apesar do mercado ou contra ele) de interações serem desenvolvidas, a fim de produzir informações ou adicionar conexões (contratos contingenciais, confiança, regras, cultura), explicando a possibilidade de coordenação. É mais necessário começar pela proliferação de relações e responder como essas conexões são suportadas tão longe (CALLON, 1999, p.186).

Essa prisão estrutural se reflete nas abordagens desenvolvidas no campo dos estudos organizacionais e na sua tendência à marginalização de aspectos relacionais. Isso é o que será analisado no próximo tópico. No entanto, para finalizar este tópico, é importante revisar o conceito de rede política, principalmente, quando se propõe o imbricamento analítico das dimensões econômica, social e política, a partir da actor-network theory, salientando-se que a abordagem econômica e social não destaca explicitamente a dimensão do poder ao enfatizar um foco na cooperação e na confiança.

A abordagem de redes políticas também começa na década de 1970, mas somente ganha destaque a partir da década de 1980 (KENIS e SCHNEIDER, 1991). A análise de redes políticas surge a partir de um entendimento na ciência política de que a idéia de política pública não poderia ser apenas explicada pelas intenções de um ou dois atores centrais - fundamentalmente, o Estado e governos -, mas por uma multiplicidade de atores interrelacionados (KENIS e SCHNEIDER, 1991, p.32). Nessa perspectiva, também se destaca a importância das coletividades organizadas na vida política e social, a inter-relação entre público e privado, bem como a existência de relações horizontais entre governos, administração e interesses organizados de maneira a privilegiar um enfoque pluralista poliárquico. ${ }^{1}$ Nesse sentido, Kenis e Schneider (1991, p.36) definem as redes políticas como "redes relativamente estáveis e de avanço das relações, nas quais são mobilizados recursos dispersos, de modo que a ação coletiva pode ser orquestrada em direção à solução de um problema comum”.

A preocupação fundamental dessa abordagem está na governança explicitada na estrutura de arranjos interorganizacionais e na formulação e implementação de políticas (MARIN e MAYNTZ, 1991). Fica evidente, portanto, uma perspectiva estrutural através da qual se quer determinar o policy making em arranjos específicos e em novas formas de governança na relação entre Estado e sociedade (KENIS e SCHNEIDER, 1991).

Por exemplo, Porras (2000, p.14) define as redes políticas como "uma estrutura configurada de vínculos, mais ou menos estáveis, que mantém um determinado número de atores, públicos e privados, na troca de recursos materiais e imateriais, em razão de sua dependência mútua, no processo de formulação, decisão e execução das políticas públicas em âmbito setorial ou subsetorial". Apesar desse autor querer em sua análise focar a capacidade associativa dos atores na formação de políticas públicas, essa conceituação lhe impõe um viés estrutural que limita a sua capacidade explicativa dos processos na rede.

Nessa perspectiva, a rede é compreendida como uma estrutura interdependente, constituída por atores e suas ligações, focada no processo de formulação e implementação de políticas, e na sua funcionalidade. Por isso, O'Toole (1997) destaca que um tratamento sério da abordagem de redes deve reespecificar conceitos

1 Pela perspectiva de Dahl (1961, 1970 e 1997), do poder concebido como influência, a fim de determinar quem ou que grupos têm mais poder. 
normativos, focando-se na sua instrumentalidade e na concretização de esforços cooperativos. Enquanto Klijn (1996) aborda o processo de institucionalização da estrutura de rede, de maneira que o jogo de atores interdependentes possa ser estabilizado em bases consensuais.

Até mesmo Marques (2000), ao enfatizar uma perspectiva relacional - negando, portanto, essa abordagem estrutural-funcionalista -, não consegue se desvencilhar de um determinismo estrutural, a partir do conceito de permeabilidade do Estado através da categoria comunidade. A dinâmica relacional explicitada no conceito de comunidade precisa, implicitamente, permear uma "pele" estrutural do Estado, revelando uma perspectiva de estruturação, a partir de uma transposição incompleta da dualidade agência-estrutura, já apresentada em Giddens (1989). ${ }^{2}$

$\mathrm{Na}$ abordagem das redes políticas, a intenção de se analisar o processo de governança por meio de associações fica limitada por amarras estruturalistas e, por isso, Latour (2003) afirma que essa abordagem não pode ser confundida com a actor-network theory. Na ANT, o poder é compreendido por meio de alianças e não por meio da dominação. ${ }^{3}$ Para a actor-network theory, as redes são constituídas e reproduzidas por meio de estratégias conscientes e práticas inconscientes, naquilo que se denomina translações, a fim de serem estabelecidas materialidades dinâmicas. Segundo Law (1992), para a ANT, a ordem é um efeito gerado pela heterogeneidade de significados, no qual a sua translação "implica transformação e possibilidade de equivalência, a possibilidade de que uma coisa (por exemplo, um ator) possa representar para outra (por exemplo, uma rede)" (LAW, 1992, p.388), de maneira que o poder não é causa, mas efeito. Nesse sentido, Callon e Latour (1981) propõem o estudo do poder - por meio de associações e dissociações - de visualizar a transformação de interações fracas em fortes ou vice-versa, capturando seus elementos duráveis e diferenças provisórias. Isto é, compreender as redes como materialidades relacionais e performativas (LAW, 1999).

\section{As redes nos estudos organizacionais}

De acordo com Faria (2001) ainda nos anos 1970, constata-se empiricamente a cooperação interfirma, notadamente pela área de marketing, e, posteriormente, uma teoria de redes começa focar as denominadas supply chain management. Dentro do campo dos estudos organizacionais, as redes passam a ser abordadas a partir da diversidade apresentada pelas relações interorganizacionais, isto é, cooperação entre firmas, alianças estratégicas, cadeias produtivas, integração de ações e programas de serviços públicos etc.

Nesses estudos interorganizacionais, é possível observar a transposição das abordagens de rede das ciências sociais em suas diferentes vertentes. Por exemplo, a cooperação entre firmas privilegia uma perspectiva econômica, centrada na teoria das trocas, ${ }^{4}$ mas também, incorpora a perspectiva da sociologia econômica, de Granovetter, como é o caso de Gulati (1998) em seu estudo sobre alianças estratégicas. Aliás, é essa abordagem socioeconômica que terá, inicialmente, uma forte influência nos estudos organizacionais - através de Powell $(1987,1990)$ - sobre novas formas organizacionais, as redes. Arranjos híbridos diferentes do mercado e das hierarquias, baseando-se na discussão de Granovetter (1985) com Williamson (1975).

Segundo Powell (1990), as redes seriam formas organizacionais alternativas, lidando melhor com limitações impostas pelo mercado e flexibilizando as hierarquias. Contudo, também alerta que "cada ponto de contato em uma rede pode ser uma fonte de conflito, tanto quanto de harmonia" (POWELL, 1990, p.305). O autor apresenta alguns exemplos dessas novas formas nas indústrias da construção, publicidade, cinematográfica, têxtil etc., destacando que essa nova forma de troca favorece a cooperação a longo termo, incentiva o

\footnotetext{
${ }^{2}$ No meu entendimento, separar a dimensão do poder num dos três eixos de estruturação restringe a compreensão de que o poder é a força motora que liga os níveis de interação e estrutura ,e não apenas as modalidades. De maneira que Giddens (1989), ao conceituar o poder como capacidade de obter resultados, não se liberta de uma concepção hobbesiana ordenadora, soberana, evidenciada pela dominação, diferentemente da concepção foulcaultiana do poder que permeia as práticas sociais, não as estruturas, formando regularidades legitimadas.

${ }^{3}$ Isso fica evidenciado na crítica a Hobbes no Despertar do Leviatã (CALLON e LATOUR, 1981).

${ }^{4}$ Mais recentemente, conforme Osborn e Hagedoorn (1997), essa ênfase econômica tem integrado também a teoria dos jogos e a teoria de custos de transação.
} 
aprendizado, a disseminação de informação e a inovação, sendo também mais adequada para condições de incerteza e de variabilidade de recursos.

Esses pressupostos têm sido sustentados por pesquisas. A cooperação tem sido analisada por meio da abordagem de redes, através de interpretações múltiplas que focam as alianças entre empresas. Aquelas que analisam a aliança cooperativa como um mecanismo temporário de expansão utilizam fundamentalmente um enfoque econômico. Enquanto outras, mais preocupadas com a formação e institucionalização da cooperação, focam diferenciações e imbricamentos, num enfoque socioeconômico que possa explicar essas configurações e os processos de sua governança, tentando compreender como essas alianças são formadas e operam em relações laterais, quase-laterais e hierárquicas.

Por exemplo, Gulati (1998) analisa a formação e operação de alianças estratégicas por meio de redes sociais e seus impactos na ação econômica, tomando como ponto de partida o problema da procura e deliberação. Por sua vez, Jones, Hesterly e Borgatti (1997) procuram demonstra que as redes, como forma de governança, trazem vantagens na solução dos problemas de adaptação, coordenação e salvaguarda de trocas. Todos parecem enfocar mais do que tudo a cooperação e sua governança, privilegiando a harmonia em relação ao conflito, esquecendo de certa maneira um dos pontos de contato da rede salientados por Powell, segundo uma característica de se afastar da dimensão do poder. Dessa forma, acabam por abordar as redes, a partir de uma perspectiva exclusivamente estrutural, mesmo quando pretendem se referir às relações sociais, esquecendo que a relacionalidade implica poder permeado nas práticas e não na dominação, um aspecto bastante evidenciado pela actor-network theory.

Ainda dentro da abordagem socioeconômica, deve ser salientada a problemática do imbricamento (embeddedness), sendo sua preocupação, compreender como as estruturas sociais afetam a vida econômica. Com esse objetivo de entendimento, a pesquisa de redes tem procurado analisar os "campos" em que as organizações estão imbricadas e como estes afetam o seu comportamento, isto é, como os interesses múltiplos de empresas de um determinado setor industrial são inter-relacionados, agregando, assim, os pressupostos da teoria da dependência de recursos e os da teoria institucional.

Uzzi (1997), por exemplo, procura demonstrar como a economia e a estrutura social são interdependentes, afetando o comportamento e as relações entre empresas. Ao apresentar as quatro formas de imbricamento classificadas por Zubin e DiMaggio (1990) como estrutural, cognitiva, política e cultural -, ele delimita seu estudo à primeira forma, indicando que as demais são baseadas numa perspectiva construtivista.

O autor parte do pressuposto de que a estrutura social dinamiza a estrutura econômica, a partir do paradoxo do imbricamento. Para Uzzi (1997), as redes representam a dinamicidade da vida econômica, por meio de relações de cooperação analisadas pelos seus antecedentes e conseqüências. Ele apresenta uma perspectiva relacional ao tratar dos antecedentes do processo de imbricamento, baseado na análise microsocial. Esses antecedentes influenciam na formatação do comportamento e das relações das empresas que serão imbricadas. Assim, ligações mais frouxamente estabelecidas por meio da troca de recursos produzem cooperação, enquanto aquelas baseadas na obrigação levam a uma rigidez. Essa análise está focada, basicamente, numa preocupação em explicar como normas de relação são contratadas, estabilizadas em diferentes formas de relacionamento interorganizacional - redes constituídas, institucionalizadas, determinantes de um padrão de comportamento.

Gulati e Gargiulo (2000) questionam essa preocupação estrutural exclusivamente apoiada em compreender as alianças estratégicas e a cooperação numa perspectiva de interdependência padronizadora de comportamentos. Procuram, também, estabelecer um imbricamento relacional, que reduz incertezas, e outro, posicional, focado no papel que os atores ocupam no sistema. ${ }^{6}$ As conclusões desses autores são as de que a formação de redes

\footnotetext{
${ }^{5}$ Concordo com Misoczky (2001) quanto à existência de incomensurabilidades intransponíveis, no conceito de campo originário de Bourdieu, e sua adoção pelo institucionalismo que quer subentender a proximidade interempresas. Essa é, na minha opinião, mais adequadamente identificada pelo conceito de setor, conforme a análise setorial francesa (MARQUES, 2000).

${ }^{6}$ Observa-se que essa preocupação com papéis no sistema é tipicamente parsoniana, compreendendo o poder como dominação por meio de consensos que transformam o conflito em cooperação.
} 
interorganizacionais é evolucionária, adequando-se ao pensamento da economia evolucionária (MURMANN et al., 2003.), dentro de uma nova faceta do determinismo econômico, certamente, permeado pelas relações sociais. Assim, a perspectiva relacional é entendida no sentido de como os atores, por meio das relações na rede, progressivamente internalizam competências e demandas de parceiros, geram confiança e reduzem incertezas, dentro ainda da ótica da ação racional. Isto é, a lógica da economia neoclássica que compreende a ação deterministicamente, a partir dos objetivos de maximização para governar a partir do foco em atores centrais, representados nas figuras do mercado e do Estado (URRY, 2002 e JESSOP, 2002), uma crítica desenvolvida pela ANT a partir desses autores.

Esse determinismo estrutural no entendimento das relações sociais não está restrito à abordagem do imbricamento social. Também as outras tipologias de imbricamento acabam revelando um estruturalismo saliente, a partir de uma perspectiva de construção social ainda limitadora, institucionalizadora, pois partem dos pressupostos implícitos de dominação na construção estruturante dos domínios de significação, proposta por Berger e Luckmann (1973) ou na teoria da estruturação de Giddens (1989). Logo, são mantidas dualidades estanques que salientam apenas uma dinamicidade nas relações, para construir estabilidades estruturadas e desvelar padrões estruturais na modelagem da agência, mesmo que reflexivamente.

Na análise da integração de ações e programas públicos, a abordagem socioeconômica também é desenvolvida. Por exemplo, Provan e Milward (1995) criticam uma visão não estrutural na abordagem de redes, salientando a importância da compreensão da racionalidade na formatação das redes para a produção de efetividade. Enquanto isso, Stevenson e Greenberg (2000) identificam falhas na teoria dos movimentos sociais em explicar a influência no policy making, de maneira a encontrar posições e estratégias centrais e periféricas, propondo compreender a formação de redes a partir da teoria da estruturação.

Entretanto, por essas perspectivas, as redes continuam como padrões cognitivos, sociais, culturais ou políticos que determinam as práticas e não, ao contrário, podendo ser continuamente construídas por estas. Assim, todos são resguardados das incertezas e do fato de que "tudo que é sólido se desmancha pelo ar", 7 pela dinâmica contínua da ação, e de relações sociais historicamente situadas.

\section{Redes na actor- network theory (ANT) e sua tradução para os estudos organizacionais}

Transpor dualidades estanques e conviver com incertezas que impedem a percepção completa da dinamicidade das relações, essa é a principal intenção da actor-network theory (LATOUR, 1994). Para Law (1994), resistir a rótulos de categorização epistemológica e falar sobre uma ordenação, em vez de uma ordem, é o que caracteriza a actor-network theory.

A origem da ANT está nos trabalhos desenvolvidos por Michel Callon, Bruno Latour e John Law no campo da sociologia da ciência e tecnologia. Eles partem do pressuposto de que o conhecimento é mais um produto social do que algo produzido por meio da operação de um método científico privilegiado (CALLON, 1980; LATOUR, 1997 e LAW, 1991), compreendendo que o conhecimento é incorporado numa variedade de formas materiais e que coloca juntamente porções e peças do social, do técnico, do conceitual e do textual, convertendo-as (traduzindo) num conjunto de materialidades heterogêneas. Por isso, Law $(1999$, p.4) afirma que a ANT deve ser compreendida como uma semiótica da materialidade, e que as redes nada mais são que essas materialidades heterogêneas. Isto é, realizações precárias e parciais em constante ordenação, na medida em que a ordem é um efeito, sendo produzida pela estabilização parcial de significações heterogêneas (LAW, 1994).

Assim, a actor-network theory se ocupa em descrever e compreender esses universos heterogêneos em sua dinâmica, olhando não apenas o estado presente de uma área num momento particular, mas também, seguindo o seu desenvolvimento e identificando algumas das dinâmicas dessa luta (CALLON, LAW e RIP, 1986). De acordo com Teil e Latour (1995), a rede existe na "coocorrência" de situações, e no fato de não existir outra

\footnotetext{
${ }^{7}$ A apropriada frase de Karl Marx e Friedrich Engels no Manifesto Comunista.
} 
ordenação que não seja contextual, dependente do processo de intervenção e da contingência das associações, na tradução de significados inter-relacionados (translações). Ela se baseia em dois movimentos integrados - um objetivo, outro subjetivo - concentrando-se mais neles do que em somar interações ou descrever estruturas (LATOUR, 1999), dentro de uma perspectiva que procura incorporar o estruturalismo ao construtivismo (CALÁS e SMIRCICH, 1999).

Nesse sentido, a ANT não trabalha com dualidades estanques e compartimentações de esquemas analíticos, entendendo que essas linhas divisórias são sempre sujeitas a negociações e mudança (LAW, 1992). Na realidade, o que se manifesta empiricamente são híbridos e não purificações ontológicas. Eles é que devem ser analisados, esses immutable mobiles, os reais mediadores capazes de traduzir as tramas do cotidiano (LATOUR, 1994). Então, para Latour (1999), a rede é uma operação, uma entidade em circulação, contendo diferentes escalas - do global ao local, e vice-versa - onde cada locus pode ser visto como uma moldura, um resumo; não podendo ser definida por categorias preestabelecidas, mas pela dinâmica das associações que produz.

Essa seria uma síntese daquilo que fundamenta a ANT, relembrando que tanto Law como Latour (1999) questionam essa estabilização teórica que rótula e cria monstruosidades, negando a dinamicidade do conhecimento (LAW, 1999) por meio de uma acumulação estruturada que lhe nega movimento (LATOUR, 1999). Por isso, é importante compreender que a actor-network theory não se constitui num campo unificado e estável de conhecimento, sendo constantemente revisada e estendida (LATOUR, 1999; LAW, 1999). Cumpre também ressaltar que uma das características da ANT é a amplitude de seu uso em diferentes contextos, não limitada a delimitações artificialmente produzidas pelos campos do conhecimento.

Por exemplo, num site específico para a actor-network theory do Departamento de Sociologia da Universidade de Lancaster, são encontrados 26 campos, nos quais essa abordagem vem sendo trabalhada. Alguns deles são ciência, tecnologia e sociedade, sociologia econômica, saúde e medicina, suporte computacional ao trabalho cooperativo, feminismo, filosofia política, análise conversacional, teoria organizacional etc. No campo da teoria organizacional, encontramos estudos focados na perspectiva de ordenação de John Law, tratando de questões diversas como o embeddedness, o poder e as subjetividades gerenciais, a virtualidade organizacional e das relações do trabalho etc.

De acordo com Kavanagh (2003), o campo dos estudos organizacionais parece indicar que a ANT tem algo a oferecer quando considerado o aumento de citações dos seus principais autores - Callon, Latour e Law - nos trabalhos desenvolvidos na área. Isso também pode ser evidenciado em número especial sobre a ANT da revista Organization, publicada pela Sage, em 1999, na qual seus organizadores salientam a capacidade dessa abordagem em analisar e explicar práticas comuns por meio de associações e "envolvimentos" 8 estratégicos, a partir de uma perspectiva relacional não distanciada de estruturas de ordem dinâmicas (HASSARD, LAW, LEE, 1999).

Além de permitir uma integração analítica do relacional com o estrutural, outro atrativo da actor-network theory parece estar na sua capacidade de análise conjunta das dimensões econômica, social e política e seus imbricamentos. A ANT permite abordar as organizações contemporâneas a partir de uma compreensão de como elas realizam a agilidade e a flexibilidade de aparências que querem exibir (LEE e HASSARD, 1999, p.403), ou seja, elas se produzem, resistindo assim à falácia da reificação do poder (MUNRO, 1999, p.430). Para Knights, Murray e Willmott (1993), o valor dessa abordagem está em esclarecer o estudo das relações interorganizacionais, não pelo enfoque dos atores per se, mas de suas relações intermediárias, evitando a relutância dos pesquisadores em teorizar sobre as redes interorganizacionais como economias políticas.

Kavanagh (2003), ao considerar as três classificações de DiMaggio (1995) do que é teoria - revestimento de leis, narrativas e iluminação -, identifica a ANT com as duas últimas. Como narrativa, ela pode ser vista como uma rede de termos e construtos que juntos fornecem uma explicação plausível de um conjunto. Como

\footnotetext{
${ }^{8}$ Originalmente, no inglês enrolling, a partir do sentido trabalhado por Callon (1998, 1999).
} 
iluminação, ela convida a olhar o familiar com novos olhos, a arrastar para fora todas as relações rapidamente congeladas e fixadas com os artifícios de antigos e veneráveis prejulgamentos.

Assim, a actor-network theory seria especialmente interessante para os estudos organizacionais, pois procura compreender analiticamente a complexidade das relações no processo de ordenação, a partir de uma linguagem focada em pessoas, textos, tecnologias e objetos. Isso permite inter-relacionar o relacional com o estrutural, superando os gaps entre micro e macro, agência e estrutura, de maneira que não ponha o poder à distância e não desconsidera o seu imbricamento com o social e o econômico. Esse aspecto é particularmente importante quando se reconhece que essas inter-relações ainda não foram plenamente desenvolvidas pelas abordagens de redes no campo dos estudos organizacionais, tendo em vista que a fragmentação e a segmentação da pesquisa não vêm assegurando uma consolidação conceitual, conforme salientado por Olivers e Ebers (1998).

\section{Traduções da actor- network theory (ANT) nos estudos organizacionais}

Neste tópico, são apresentados alguns estudos realizados com base na ANT, observando que essa abordagem tem sido adotada na análise de diferentes fenômenos organizacionais e interorganizacionais. Essas pesquisas têm focado desde o processo de inovação tecnológica até comunidades de práticas e sua influência no processo gerencial.

Knights, Murray e Willmott (1993) analisam a implantação do comércio eletrônico na indústria de seguros no Reino Unido, a partir da construção da rede Switchco, constituída por 20 companhias de seguro de grande e médio porte. Como salientam os autores, a actor-network theory é "um recurso analítico para sair dos tradicionais modelos de análise baseados na linearidade e na racionalização, pois facilita um maior entendimento sobre a formação e a dinâmica daquilo que se desenvolve" (KNIGHTS, MURRAY e WILLMOTT, 1993, p.976). Assim, em sua pesquisa, eles procuram demonstrar como a rede Switchco se constitui numa forma de knowledge work, que se constrói, por meio de translações, para redirecionar as vantagens competitivas do setor, independentemente dos serviços de distribuição do setor financeiro.

Assouline e Oerlemans (2001) analisam como a agricultura sustentável se consolida a partir da formação de redes que integram a produção e a distribuição de produtos orgânicos, a partir do estudo de casos na Dinamarca, França e Holanda. Em sua análise, os autores salientam como as redes são constituídas por um processo de aprendizagem, a partir da adoção de práticas inovadoras e da translação de concepções divergentes de agricultura sustentável entre diferentes atores envolvidos com o objetivo de consolidar técnica e coletivamente um modelo europeu de agricultura sustentável.

Swan, Scarbrough e Robertson (2002) analisam como redes interorganizacionais de profissões e ocupações se constituem em comunidades de práticas e têm importância para a aprendizagem e a inovação organizacional, a partir da observação, no contexto europeu, de um projeto desenvolvido na terapia do câncer de próstata. A ANT é um recurso analítico para se escapar do tradicional afastamento do discurso gerencial da dimensão do poder, a partir da compreensão de que ele está definitivamente integrado na tentativa de construção de comunidades de práticas.

Giroux e Taylor (2002) criticam a abordagem de aprendizagem organizacional formulada por Nonaka e Takeuchi, pois entendem que a aprendizagem ocorre por meio de associações e dissociações, conforme aborda a ANT. Para isso, os autores estudam um caso de implantação de projeto de qualidade total, reportando como a qualidade é progressivamente aceita como solução, a partir de diversas translações que procuram justificá-la.

Outros trabalhos com um caráter mais conceitual também têm abordado a actor-network theory no campo dos estudos organizacionais. Por exemplo, Tatnall (2003) compara o modelo de difusão da inovação com a proposta de translação da inovação, desenvolvida por Latour (1997), no caso de sistemas de informação. Conclui ser a translação uma abordagem mais adequada, por sua capacidade de considerar conjuntamente o técnico e o social. Aliás, a ANT tem sido particularmente adotada pela a área de sistemas de informação, exatamente por essa sua capacidade de abordar o sociotécnico, de forma integrada (MUTCH, 2002). 
Esse aspecto também é salientado por Kavanagh (2003), quando afirma que essa capacidade da actor-network theory de lidar relacionalmente com elementos humanos e não-humanos a partir do uso imaginativo da semiótica favorece, particularmente, os estudos organizacionais sobre a complexidade dos fenômenos. Assim, a ANT tem sido integrada aos estudos organizacionais, a fim de dar significado à relacionalidade (PARKER, 1998), a partir de uma abordagem recursiva distinta da moderna e da pós-moderna, investindo em ligar um realismo empírico a uma ontologia relativista (LEE e HASSARD, 1999). Nessa perspectiva, é possível integrar a dimensão relacional à estrutural, um recurso analítico fundamental para compreender e explicar as redes interorganizacionais, na diversidade de seus contextos e práticas.

\section{Considerações finais}

De acordo com Law (1992, p.390), "as estruturas sociais seriam melhor tratadas como verbo do que como nome". Nesse sentido, é importante compreender as redes em seus constantes movimentos e não se apegar a um modelo ou a um arranjo definitivo que as estabilize, reconhecendo que a realidade social e, conseqüentemente, organizacional é por si só dinamizada pelas relações de que é constituída.

Essa perspectiva dinâmica da actor-network theory é criticada por Reed (1997, p.25), argumentando que esse foco no processo de ordenação faz com que "instituições, organizações e atores sejam vistos como produto ou efeito do nível micro dos processos de ordenação e modelação, formando cadeias interacionais, nas quais a estruturação social é praticamente realizada". Mas não seria isso mesmo que caracteriza o universo social? A idéia da construção socialmente situada que objetiva a realidade social, conforme propõe Max Weber.

Nessa discussão, é importante salientar que um dos grandes problemas nas análises estruturais de redes interorganizacionais está exatamente nessa preocupação em ver como as estruturas produzem inter-relações estabilizadas, modelando comportamentos organizacionais e interorganizacionais. Essa acomodação da agência no comportamental, que acaba marginalizando o relacional, é um aspecto limitador para se analisar como relações interorganizacionais são produzidas e processadas por meio de práticas em estabilidades parciais, como, por exemplo, as alianças estratégicas.

Reed (1997) critica ,então, a ANT por privilegiar um enfoque que desinstitucionaliza a concepção de organização e não se preocupa em ver como estruturas institucionalizadas moldam e modificam o processo de interação social, negando, de acordo com ele, as estruturas e dando uma relativa independência aos agentes. Essa critica de Reed (1997) revela uma contradição com outro ponto pelo qual a actor-network theory é criticada, que é a sua postura não antropocêntrica. Aparentemente, seu argumento esvazia a agência e atribui força à determinação de "entidades" estruturais supra-humanas, como se estrutura e agência fossem por si só excludentes, esquecendo que Karl Marx há muito demonstrou que determinações estruturais (o capital) só podem ser compreendidas a partir das relações sociais: o processo de trabalho.

Ao contrário do que sugere Reed (1997), a ANT não quer privilegiar um dos lados da dualidade do macro e do micro, da estrutura e da agência, pois ela nega em si essas dualidades, perpassando-as em sua análise. De acordo com Latour (1994), é a modernidade que impõe essas ontologias purificadoras nada assemelhadas com as práticas, tendo em vista que não reconhece a multiplicidade de formas parcialmente estabilizadas no contínuo jogo de translações na busca de aliados para traduzir "os tantos mundos que existem e as tantas linguagens que existem para falar deles" (CZANIAWSKA e SÉVON, 1996, p.07).

Não se vive nesse mundo purificado de ordens perfeitas. Pelo contrário, por isso é importante reconhecer que jamais fomos modernos (LATOUR, 1994), pois o ideal universal da razão iluminista não foi alcançado, e, conseqüentemente, "a realidade não precede às práticas mundanas (...) mas é modelada por elas" (MOL, 1999, p.75), no sentido estratégico apontado por Foulcaut $(1982,1984)$. Este considera que o poder das práticas atravessa o corpo social "como algo que circula, ou melhor, como algo que só funciona em cadeia" (FOUCAULT, 1982, p.183), a partir de uma correlação de forças em busca de hegemonias.

Assim como Foucault, a abordagem da actor-network theory procura examinar as práticas sociais e sua transformação no tempo através dos processos de associações e dissociações que produzem materialidades 
heterogêneas. Por sua vez, esses processos e práticas somente podem ser compreendidos pela total permeabilidade do poder. A ANT é criticada por Giddens, exatamente, por adotar esse entendimento. De acordo com ele, trata-se de uma perspectiva reducionista, restringindo tudo ao poder que "torna-se um fenômeno misterioso que paira em todo lugar e suporta todas as coisas" (GIDDENS, 1995 apud KAVANAGH, 2003, p.5).

Mais uma vez, é necessário insistir que Giddens tem uma concepção de poder diferenciada daquela que permeia a abordagem da ANT e de Foucault. Foucault (1984) talvez responda melhor a essa provocação, explicando o que não é poder: não são grupos de instituições e mecanismos, não são sistemas de dominação. Para ele, o poder deve ser compreendido "como a multiplicidade de correlações de força imanente ao domínio onde se exercem e constituem sua organização" (FOUCAULT, 1984, p.88), conseqüentemente, o poder emerge de contextos, não sendo um ponto central para a soberania e a dominação, pois ele é um "suporte móvel das correlações de força que, devido a sua desigualdade, induzem continuamente a estados de poder, mas sempre localizados e instáveis" (FOUCAULT, 1984, p.89).

De acordo com Clegg (1989), Giddens, sim, é reducionista, ao não se livrar de uma concepção de poder como dominação dentro de um sentido causal e mecânico na racionalização da ordem baseada no conceito de soberania implicitamente inserido pelo pensamento de Hobbes. Como ressaltam Callon e Latour (1981, p.278), para Hobbes, a soberania nada mais é que a soma de vontades da multidão. Ela "torna-se a pessoa que diz o que os outros são, o que eles querem e o que eles valorizam". Significa mais uma concepção que reforça apenas a "entidade" estrutural supra-humana e reduz a agência ao limbo da reprodução de padrões, ou como na teoria da estruturação de Giddens (1989), a uma ordem que é possível por meio de regularidades, de sistemas reproduzidos.

De acordo com Callon e Latour (1981), a compreensão do poder não é revelada pelo reconhecimento de uma vontade que se impõe sobre as demais, mas sim, pelo entendimento de como vontades são traduzidas numa vontade parcialmente estabilizada. Assim, para eles, a concepção do ator-rede permite compreender como elementos são capazes de curvar o espaço em torno de si, fazendo os outros dependentes e traduzindo suas vontades numa linguagem particular que faz mudanças no conjunto de elementos e conceitos habitualmente usados para descrever o mundo social e natural (CALLON e LATOUR, 1981).

Esse entendimento do poder nas práticas, e não a partir de estruturas de governança, é fundamental para a análise das redes interorganizacionais, pois ele efetivamente auxilia na compreensão dos processos de confiança, cooperação e conflito dessas relações. Também, a compreensão de que as relações não são apenas definidas pelas estruturas - nem tampouco se constituem em simples interações, mas são produzidas por meio de ordenações móveis de força - pode contribuir para analisar os imbricamentos em que o social dinamiza o econômico pela disputa e conformação de práticas, e não apenas pela formatação de comportamentos.

Mas, como a actor-network theory se propõe a contribuir com o campo dos estudos organizacionais? De acordo com Law (1992), a ANT pode contribuir com os estudos organizacionais através de um conjunto de questões para explorar os precários mecanismos da organização:

"Quais são os tipos de porções e peças heterogêneas criadas ou mobilizadas e justapostas para produzir efeitos organizacionais? Como são justapostas? Como são resistentes a sujeições? Como isso se refere (se de todo) à materialidade e à transportabilidade necessária ao padrão organizacional de relações sociais a ser realizado? Quais as estratégias representadas por meio da rede do social como parte disso? Quão longe elas se espalham? Como amplamente elas são representadas? Como elas interagem? Como isso se refere (se de todo) ao cálculo organizacional pretendido? Como (se de todo) os resultados desse cálculo são traduzidos em ação? Como isso se refere (se de todo) às porções e peças heterogêneas que completam a organização, produzindo uma relação entre periferia e centro? Em outras palavras, como um centro deve chegar a falar dos esforços (e aproveitá-los) do que tem sido transformar uma periferia? Como é isso que um gerente administra? [concluindo] Vista dessa maneira, a organização é uma realização, um processo, uma conseqüência, um conjunto de resistências sujeitadas, um efeito precário. Seus componentes - as 
hierarquias, os arranjos organizacionais, as relações de poder e os fluxos de informação - são as conseqüências incertas de uma ordenação de materiais heterogêneos. Isso é o que a actor-network theory analisa e desmistifica. Desmistifica o poder do poderoso. Isso que dizer, em última instância, que não existe diferença em espécie, grande dívida, entre o poderoso e o miserável. Mas também quer dizer que não existem tais coisas como última instância. E, uma vez que não existe última instância, na prática, existem reais diferenças entre o poderoso e o miserável, diferenças em métodos e materiais que eles dispõem para se produzirem. Nossa tarefa é estudar esses materiais e métodos, para compreender como eles realizam a si próprios e para distinguir o que poderia e quase sempre seria de outro modo"(LAW, 1992, p.391).

Certamente, não se quer aqui propor que a actor-network theory encontre o pote de ouro no final do arco-íris, dando continuidade ao joguete de Kanavagh (2003) com o título de seu artigo “The Wizard of Oz?". A ANT é apenas uma abordagem que pode apresentar algumas contribuições para se desfazer os intricados nós, na análise dos fenômenos interorganizacionais. No entanto, cabe salientar que trata-se de uma abordagem adequada para aqueles que precisam e conseguem lidar com as incertezas constantes do porvir, e que gostam de potencializar as transformações. Para aqueles que apreciam mais o porto seguro das certezas e das ordens estabilizadas, talvez seja melhor manter a distância e continuar no seu mundo único e mágico de estruturas e sistemas. 


\section{Referências bibliográficas}

ASSOULINE, G.; OERLEM ANS, N. Organizational changes for consolidating sustainable agriculture and rural development in Europe: the role farmer's networking strategies. Paper apresentado no The $7^{\text {th }}$ European Roudtableon Cleaner Production - IIIEE, Lund, Suécia, 2001.

BERGER, P.; LUCKMANN, T. A construção social da realidade. 4. ed. Petrópolis: Vozes, 1973.

CALÁS, M. B.; SM IRCICH, L. Past postmodernism reflections and tentative directions. Academic of Management Review, v.24, n.4, p.649$71,1999$.

CALLON, M. Struggles and negotiations to define what is problematic and what is not: the sociology of translation. In: KNORR- CETINA, K.; KROHN, R.; WHITLEY, R. (Eds.). The social process of scientific investigation. Dordrecht, Holanda: Ridel, 1980. p.197-220.

. An essay on framing and overflowing: economic externalities revisited by sociology. In: CALLON, M. (Ed.). The laws of the markets. Oxford: Blackwell, 1998. p.244-69.

Actor-network theory - the market test. In: LAW, J.; HASSARD, J. Actor- network theory and after. Oxford: Blakcwell Publishers, 1999. p.181-95.

; LATOUR, B. Unscrewing the big leviathan: how actors macro- structure reality and how sociologists help them to do so. In: KNTORR-CETINA, K.; CICOUREL, A.V. Advances in social theory and methodology, toward an integration of micro and macrosociologies. Boston: Routledge \& Paul Kegan, 1981. p.277-303.

; LAW, J.; RIP, A. Mapping the dynamics of science and technology. London: Macmillan Press, 1986.

CLEGG, S. Frameworks of power. London: Sage, 1989.

CZANIAWSKA, B.; SÉVON, G. Introduction: In: CZANIAWSKA, B.; SÉVON, G.(Eds.). Translating organizational change. Berlim: de Gruyter, 1996. p.01-12.

DAHL, R. A. Who governs? Democracy and power in an American city. New Haven: Yale University Press, 1961.

A moderna análise política. 2. ed. Rio de Janeiro: Lidador, 1970.

Poliarquia, participação e oposição. São Paulo: EDUSP: 1997.

DIM AGGIO, P. Comments on what theory is not. Administrative Science Quarterly, v.40, p.391-97, 1995.

EMIRBAYER, M. Manifesto for a relational sociology. American Journal of Sociology, v.103, n.2, p.281-317, 1997.

; GOODWIN, J. Network analysis, culture and the problem of agency. American Journal of Sociology, v.99, n.6, p.1411-54, 1994.

FARIA, A.. Teorias de estratégia, estratégias de pequenas empresas e 'estratégias teóricas': estudo de caso em rede assimétrica no setor de telecomunicações no Brasil. In: Enanpad, 25. Anais... Campinas, Anpad, 2001.

FOUCAULT, M. Microfísica do poder. 3. ed. Rio de Janeiro: Graal, 1982.

. História da sexualidade. 5. ed. Rio de Janeiro: Graal, 1984. v.l.

GIDDENS, A. A construção da sociedade. São Paulo: Martins Fontes, 1989.

GIROUX, H.; TAYLOR, J. The justification of knowledge, tracking the translations of quality. Management Learning, v.33, n.4, p.497-517, 2002.

GRANOVETIER, M. The strength of weak ties. American Journal of Sociology, v.78, n.6, p.1360-80, 1973.

Economic action and social structure: the problem of embeddedness. American Journal of Sociology, v.35, n.3, p.481-510 1985.

Economic institutions as social constructions: a framework for analysis. Acta Sociologica, v.35, n.3, p.3- 11, 1992.

GULAT, R. Alliances and networks. Strategic Management Journal, v.19, p.293-317, 1998.

; GARGIULO, M. Where do interorganizational networks come from? In: WEESIE, J.; RAUB, W (Ed.). The management of durable relations: theoretical models and empirical studies of households and organizations. Amsterdam: Thelathesis, 2000.

HASSARD, J.; LAW, J., LEE, N. Organization, v.6, n.3, p.387-90, 1999. (Preface).

JESSOP, B. The dynamics of partnership and governance. Site de papers da ANT do Departamento de Sociologia - Universidade de Lancaster, Reino Unido. Disponível em: <www.comp.lancs.ac.uk/sociology>. Acesso em: 14 agosto 2002.

JONES, C.; HESTERLY, W. S.; BORGATTI, S. P. A general theory of network governance: exchange conditions and social mechanisms. Academy of Management Review, v.22, n.4, p.911-45, 1997.

KAVANAGH, D. ANT: The Wizard of OS? Following the yellow brick road. Disponível em: <http://www.keele.ac.uk/depts/stt/cstt2/ant/>. Acesso em: 22 janeiro 2003. 
KENIS, P.; SCHNEIDER, V. Policy networks and policy analysis: scrutinizing de new analytical toolbox. In: MARIN, B.; MAYNTZ, R. (Ed.). Policy networks empirical evidence and theoretical considerations. Boulder, CO, USA: Westview Press, 1991. p.25-59.

KLIJ N, E- H. Analyzing and managing policy processes in complex networks: a theoretical examination of the concept policy network and its problems. Administration and Society, v.28, n.1, p.90-119, 1996.

KNIGTHS, D.; MURRAY, F.; WILLM OTT, H. Networking as knowledge: a study of strategic interorganizational development in the financial services industry. Journal of Management Studies, n.30, v.6, p.975-95, 1993.

LATOUR, B. Jamais fomos modernos, ensaio de antropologia simétrica. São Paulo: Editora 34, 1994. Ciência em Ação. São Paulo: UNESP, 1997.

On recalling ANT. In: LAW, J.; HASSARD, J. Actor-network theory and after. Oxford: Blakcwell Publishers, 1999. p.15-25.

An advertisement for we have never been modern. Disponível em: <http://www.stanford.edu/ rvalenza/bruno.html>. Acesso em: 27 fevereiro 2003.

LAW, J. A sociology of monsters, essays on power, technology and domination. London: Routedge, 1991. . Notes on the theory of the actor-network: ordering, strategy and heterogeneity. Systems Practices, v.5, n.4, p.379-393, 1992. Organizing modernity. Oxford: Blackwell, 1994.

After ANT: complexity, naming and topology. In: LAW, J.; HASSARD, J. Actor- network theory and after. Oxford: Blakcwell Publishers, 1999. p.01-15.

LEE, N.; HASSARD, J. Organization unbound: actor- network theory, research strategy and institutional flexibility. Organization, v.6, n.3, p.391-403, 1999.

MARIN, B.; MAYNTZ, R. Introduction: studying policy networks. In: MARIN, B.; MAYNTZ, R. (Ed.). Policy networks empirical evidence and theoretical considerations. Boulder, CO, USA: Westview Press, 1991, p.25-59.

MARQUES, E. C. Estado e redes sociais: permeabilidade e coesão nas políticas urbanas no Rio de Janeiro: Revan ; São Paulo: Fapesp, 2000.

MISOCZKY, M.C. Campo do poder e ação em Bourdieu: implicações de seu uso em estudos organizacionais. In: Enanpad 25. Anais... Campinas, Anpad, 2001.

MOL, A. Ontological politics, a word and some questions. In: LAW, J.; HASSARD, J. Actor-network theory and after. Oxford: Blakcwell Publishers, 1999. p.74-89.

MUNRO, R. Power and discretion: memberships work in the time of technology. Organization, v.6, n.3, p.387-90, 1999.

MURM ANN, J. P., et al. Evolutionary thought in management and organization theory at the beginning of the new millennium. Journal of Management Inquiry, v.12, n.1, p.22-40, 2003.

MUTCH, A. Actors and networks or agents and structures: towards a realist view of information systems. Organization, v.9, n.3, p.477-96, 2002.

OTOOLE, L. Treating networks seriously: practical and research-based agendas in public administration. Public Administration Review, v.57, n.1, p.45-52, 1997.

OLIVER, A.; EBERS, M. Networking networks studies: an analysis of conceptual configuration in the study of interorganizational relationships. Organization Studies, v.19, n.4, p.549-83, 1998.

OLIVER, C. Determinants of interorganizational relationships: integration and future directions. Academy of Management Review, v. 5, n.2, p.241-65, 1990.

OSBORN, R.; HAGEDOORN, J. The institutionalization and evolutionary dynamics of interorganizational alliances and networks. Academy Management Review, v.40, n.2, p.261-78, 1997.

PARKER, M. Judgement day cyborganization, humanism and posmodernism ethics. Organization, v.5, n.4, p.503-18, 1998.

PORRAS, J. I. Policy networks ou redes de políticas públicas: su aplicación al estudio de los vínculos entre las asociaciones de interés y el estado. Paper. FAO/ONU, 2000.

POWELL, W. W. Hybrid organizational arrangements: new form or transitional development? California Management Review, v.30, n.1, p.67-86, 1987.

. Neither market nor hierarchy: network forms of organization. Research in Organizational Behavior, v.12, p.295- 336, 1990.

PROVAN, K. G.; MILWARD, H. B. A preliminary theory of interorganizational network effectiveness: a comparative study of four community mental health systems. Administrative Science Quartely, v.40, n.1, p.01-33, 1995. 
REED, M. I. In praise of duality and dualism: rethinking agency and structure in organizational analysis. Organization Studies, v.18, n.1, p.21-42, 1997.

STEVENSON, W. B.; GREENBERG, D. Agency and social networks: strategies of action in a social structure position, opposition and opportunity. Administrative Science Quarterly, v.45, n.4, p.651-78, 2000.

SWAN, J.; SCARBROUGH, H.; ROBERTSON, M. The construction of 'communities of practice' in the management of innovation. Management Learning, v.33, n.4, p.447-96, 2002.

TATNALL, A. Information systems innovation - two different models. Disponível em:

$<w w w . b u s i n e s s a n d l a w . v u . e d u / i n f o s y s p a p e r s o n \_T h e o r i e s . p d f>$. Acesso em: 24 fevereiro 2003.

TEIL, G.; LATOUR, B. The hume machine, can association networks do more than formal rules? SEHR, v.4, n.2, 1995.

URRY, J. Globalizaton and citizenship. Site de papers da ANT do Departamento de Sociologia da Universidade de Lancaster, Reino Unido. Disponível em: <www.comp.lancs.ac.uk/sociology> Acesso em: 14 agosto 2002.

UZZI, B. The sources and consequences of embeddedness for the economic performance of organizations. American Sociological Review, v.61, p.674-98, 1996.

Social structure and competition in interfirm networks: the paradox of embeddedness. Administrative Science Quarterly, v.42, n.1. p.35-67, 1997.

WILLIANSON, O. Markets and hierarchies. New York: Free Press, 1975.

ZUBIN, S.; DIMAGGIO, P. Structures of capital: the social organization of the economy. New York: Cambridge University Press, 1990. 